\title{
Tri-Logic - Proposta Lúdica Gamificada para o Ensino e Aprendizagem da Lógica de Programação com o Uso da Mineração de Dados como Ferramenta de Auxílio ao Professor
}

\author{
Brenda Barbosa, Bruno de Sousa Much, Carla Odete Balestro Silva, Marcio \\ Bigolin, Sandro José Ribeiro da Silva
}

Instituto Federal de Educação, Ciência e Tecnologia do Rio Grande do Sul - Campus Canoas

brenda.anghinoni@gmail.com muchsousa@gmail.com,carla.silva@canoas.ifrs.edu.br, márcio.bigolin@canoas.ifrs.edu.br, sandro.silva@canoas.ifrs.edu.br

\begin{abstract}
Difficulties are commonly found in learning programming for the construction of computational systems. One of the alternatives to deal with this problem is the development of environments such as the teaching tool and the learning of logic and programming, basic concepts for any programming language. Thus, the development of Tri-Logic began, which proposes a support environment to the teaching of the discipline, which is found in electronic screen or online monitoring of its stages through the use of educational data mining techniques.
\end{abstract}

Resumo. Comumente são encontradas dificuldades na aprendizagem de programação para construção de sistemas computacionais. Uma das alternativas para enfrentar este problema é o desenvolvimento de ambientes gamificados como ferramenta de ensino e aprendizagem de lógica de programação - conceitos básicos para qualquer linguagem de programação. Diante disso, iniciou-se o desenvolvimento do Tri-Logic, que propõe um ambiente de apoio ao ensino desta disciplina, aliando aos jogos eletrônicos o monitoramento online de suas etapas através do uso de técnicas de mineração de dados educacionais.

\section{Introdução}

A lógica de programação é uma disciplina básica e essencial para todos aqueles que desejam aprender uma linguagem de programação, aplicada no primeiro ano/semestre de qualquer curso na área de desenvolvimento de sistemas em Tecnologia da Informação (TI). Um dos maiores obstáculos em cursos desta área é o alto índice de reprovação e/ou evasão nas disciplinas relacionadas a lógica [ROCHA et al. 2010]. Alguns estudos indicam que a grande barreira no aprendizado da programação é a falta de motivação dos alunos e a dificuldade de conseguir acompanhar o ritmo proposto pelos professores [ALMEIDA, E. S. DE et al. 2002].

\section{Metodologia}

O desenvolvimento do ambiente gamificado para este projeto - nomeado Tri-Logic - foi implementado a partir do levantamento dos requisitos necessários junto aos alunos e 
professores do Instituto Federal de Educação, Ciência e Tecnologia do Rio Grande do Sul (IFRS) - Campus Canoas, com base em um Framework para gamificação. Após a identificação dos requisitos, foi gerado um protótipo e levado para testes práticos cujos resultados obtidos foram avaliados e possibilitaram o desenvolvimento da atual versão.

\section{Gamificação}

Como resultado da popularização dos jogos eletrônicos e de sua capacidade intrínseca de motivar a ação, resolver problemas e potencializar a aprendizagem na mais diversas áreas [WERBACH, K.; HUNTER, D 2012], a gamificação é uma estratégia que vem surgindo com o objetivo de melhorar a motivação e o engajamento do aluno em sala de aula, através da utilização de elementos dos jogos (mecânicas, estratégias e pensamentos) fora de seus contextos, com a finalidade de auxiliar na solução de problemas e promover aprendizagens [PAULO, R.; JÚNIOR, M.; BONIATI, B. B 2015].

O conceito de lúdico é próximo ao conceito de gamificação. O uso de ferramentas lúdicas amplia o interesse dos alunos na disciplina, facilitando o processo de aprendizagem. Essa motivação, estimulada pelo uso de jogos, resulta na diminuição do índice de evasão de alunos na área da computação [RAMOS, V. 2015].

\section{Desenvolvimento do Tri-Logic}

Iniciado em 2016, o ambiente nomeado Tri-Logic conta com exercícios lúdicos no intuito de estimular o aluno a compreender conceitos básicos em um contexto geral, sobre descrição narrativa, fluxogramas, manipulação de variáveis, utilização de tabelas com a introdução dos conceitos de vetores e matrizes, cláusulas condicionais (se/então/senão) e estruturas de repetição (para/repita-até e faça-enquanto).

Ao acessar o ambiente o aluno será apresentado ao mesmo pelo seu agente animado Bigolito (Figura 1). A implementação de um agente pedagógico animado desempenhando o papel de um assistente integrado ao ambiente possa contribuir para a melhoria do processo de ensino-aprendizagem dos alunos que o utilizarem [REATEGUI et al. 2006].

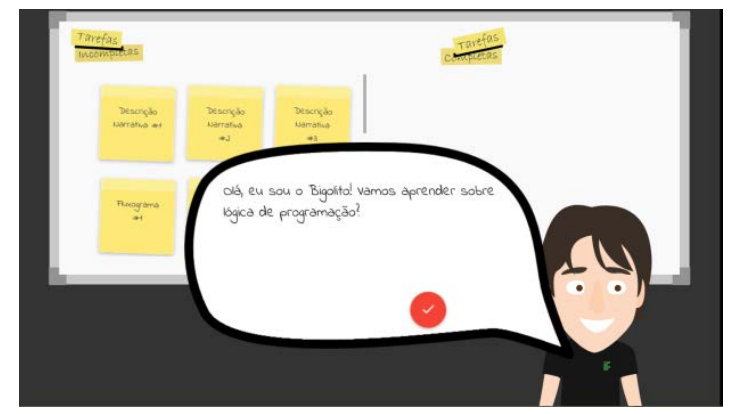

Figura 1. Imagem da página inicial do ambiente, onde se encontram as fases.

O arquivo CSS (folha de estilos) game-objects.css contém os diversos estilos que são aplicados aos objetos do jogo. A interatividade da cena é definida por um arquivo JavaScript, que, utilizando-se das estruturas do framework, monta a Controller da cena.

\section{Mineração de Dados Educacionais}


VI Congresso Brasileiro de Informática na Educação (CBIE 2017)

Anais do XXVIII Simpósio Brasileiro de Informática na Educação (SBIE 2017)

Com a mineração de dados educacionais, objetiva-se identificar automaticamente perfis de comportamento a serem tratados de forma específica. Os dados recolhidos serão monitorados, o que permitirá detectar falhas, prever comportamentos, aumentar o desempenho, realizar ajustes finos para remover problemas que atrapalhem 0 ensino/aprendizagem ou desagradem de alguma maneira o aluno, dentre outras possibilidades.

\section{Avaliações Preliminares}

Com o protótipo do Tri-Logic, ainda em 2016, foram realizados testes com os alunos através de uma oficina para verificar as possibilidades e aceitação do ambiente implementado. Participaram 20 alunos do primeiro ano do Curso Técnico em Desenvolvimento de Sistemas integrado ao Ensino Médio do Instituto Federal de Educação, Ciência e Tecnologia do Rio Grande do Sul (IFRS) - Campus Canoas, com idades entre 13 e 16 anos.

A atividade teve uma duração total de uma hora e foi proposto que os alunos jogassem todos os níveis do jogo e em seguida respondessem a um questionário onde os mesmos poderiam expor suas opiniões sobre o ambiente, que atingiu resultados satisfatórios. Ao serem questionados sobre o quanto o ambiente contribuiu para o aprendizado da lógica de programação os alunos, em geral, consideraram que o ambiente foi proveitoso. 90,9\% dos alunos sentiram-se motivados a seguirem aprendendo lógica de programação. Também foram recolhidas críticas e sugestões que possibilitaram modificações no protótipo e no desenvolvimento da versão atual do TriLogic, visando melhorias em seu desempenho.

\section{Referências}

ALMEIDA, E. S. DE et al. AMBAP: Um AMBAP: Um Ambiente de Apoio ao aprendizado de Programação. Anais do 6o Congresso de Iniciação Científica ASSER - UNICEN, p. 91, 2002.

PAULO, R.; JÚNIOR, M.; BONIATI, B. B. LogicBlocks : Uma Ferramenta para o Ensino de Lógica de Programação. Anais do EATI - Encontro Anual de Tecnologia da Informação e Semana Acadêmica de Tecnologia da Informação. Anais...Frederico Westphalen: 2015

Ramos, V.; Freita, M.; Galimbert, M.; Mariani, A.C.; Wazlawick, R. A Comparação da realidade mundial do ensino de programação para iniciantes com a realidade nacional: Revisão sistemática da literatura em eventos brasileiros. In: Simpósio brasileiro de informática na educação SBIE; 2015.

REATEGUI, E. B. et al. Agentes Pedagógicos Animados. Renote Revista Novas Tecnologias na Educação, v. 4, n. 2, p. 1-10, 2006.

ROCHA, P. S. et al. Ensino e Aprendizagem de Programação: Análise da Aplicação de Proposta Metodológica Baseada no Sistema Personalizado de Ensino. RENOTE Revista Novas Tecnologias na Educação, v. 8, n. 3, p. 1-11, 2010.

WERBACH, K.; HUNTER, D. For the Win: How Game Thinking Can Revolutionize Your Business. [s.l.] Wharton Digital Press, 2012. 